durch Zentrifugieren, Dialyse oder Agarfiltration durchzuführen. Das Ultrazentrifugieren gibt gute Resultate vor allem bei einer grösseren Menge einer genügend konzentrierten Suspension von Bakteriophagen, besonders wenn es sich nicht um Phagen mit sehr langen, dünnen und brüchigen Schwänzen und solche mit Fasern an den Schwänzen handelt. Mit einer Dialyse kann man eine Reihe von Stoffen mit grösseren Molekülen nicht beseitigen. Die Agarfiltration ist in ihrer Anwendung ebenfalls begrenzt, vor allem durch die kleine. Flüssigkeitsmenge, die pro Filterflächeneinheit verarbeitet werden kann, und die Unmöglichkeit, eine beliebige Membran zu wählen, die dann als Objektträger für die elektronenmikroskopische Beobachtung dient.

Als Methode, die die erwähnten Verfahren günstig ergänzen kann, beniitzten wir die Ultrafiltration durch Kollodium-Membranfilter ${ }^{5}$ mit einem durchschnittichen Porendurchmesser von $300 \AA$ und einer kreisförmigen Filtrationsfläche von $2,5 \mathrm{~cm}^{2}$ (Durchmesser $18 \mathrm{~mm}$ ), bei einem Überdruck von 1,25 atm von Stickstoff oder Luft. Auf den Membranfilter gossen wir $1 \mathrm{ml}$ einer 2\%igen Ammoniumazetatlösung in Wasser, deren $\mathrm{pH}$ auf den Naturalwert durch Ammoniumkarbonat eingestellt worden war, und liessen $0,6 \mathrm{ml}$ Flüssigkeit durch einen Filter durchfliessen. Dann fügten wir $3 \mathrm{ml}$ der Phagensuspension hinzu, die $8 \times 10^{7}$ bis $10^{10}$ Phagen $/ \mathrm{ml}$ enthielt und von grösseren Teilchen durch Zentrifugieren bei $12000 \mathrm{~g}$ gereinigt worden war. Wir filtrierten diese Menge, bis über dem Filter ungefähr $0,4 \mathrm{ml}$ übrigblieb. Dann fügten wir $1 \mathrm{ml}$ einer neutralen Lösung der oben erwähnten flïchtigen Salze hinzu und filtrierten abermals, bis ïber dem Filter ungefähr $0,4 \mathrm{ml}$ übrigblieb. Dies führten wir im ganzen 4mal durch. Die Konzentration der gelösten Stoffe, die den Filter passierten, hat sich also durch dieses Verfahren ungefähr 250mal verringert. Dann fügten wir $\mathrm{zu}$ der Phagensuspension, die über dem Filter aufgefangen war, $2 \mathrm{ml}$ der neutralen Lösung von flüchtigen Salzen hinzu, wuschen damit den Filter, gossen sie in ein besonderes Gefäss $a b$, nahmen die ganze Filtrationseinrichtung auseinander und reinigten sie durch Auswaschen mit destilliertem Wasser. Dann filtrierten wir die Phagensuspension aus der ersten Filtrierung durch einen gleichen Vorgang entweder durch dieselbe oder eine neue Filtrationsmembran mit der gleichen Porosität. Die resultierende Verdünnung der gelösten Stoffe betrug also ungefähr das 65000 fache. Alle Änderungen des Filtrationsdruckes und der Ionenstärke musste man so zart als möglich durchführen.

So gewaschene Bakteriophagen benützten wir zur Herstellung der Präparate, die dann positiv mit Uranylazetat oder negativ mit einer neutralen Lösung von Natriumphosphowolphramat gefärbt oder metallbedampft wurden. Die Qualität des Durchwaschens, die Unversehrtheit der Teilchen und die Färbung ermöglich-

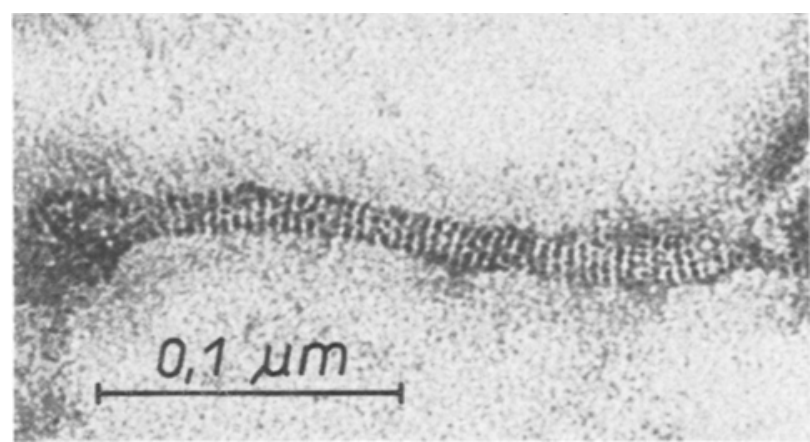

Die Struktur des Phagenschwanzes des Bakteriophagen 81 Straphylococcus aureus. Präparat mit Uranylazetat gefärbt. Elektronenoptische Vergrösserung $\times 35800$. Präparat: S. KLHU゚FKovÁ, B. Liška. Aufnabme: $V_{L}$. Drahoš, Institut der Instrumententechnik der Tschechoslowakischen Akademie der Wissenschaften.

ten, Details von ungefähr $20 \AA \AA$ in der Struktur der Schwänze und in den Hüllen der Phagenköpfe zu beobachten (Figur). Zum Zwecke einer noch vollkommeneren Reinigung und Eindickung ist es möglich, eine so zubereitete Bakteriophagensuspension in einem Cäsiumchloridgradienten $z u$ zentrifugieren und sie bei der Filtrierung in eine CsCl-Lösung zu überführen.

Bei der Reinigung von Mykoplasmen und L-Formen ist es im Hinblick auf die grösseren Ausmasse dieser Objekte nicht nötig, Filter mit so kleinen Poren zu benützen, und man kann dann einen niedrigeren Filtrationsdruck anwenden. Deshalb eignet sich dafür die übliche Unterdruckfiltration durch Membranfilter mit einer durchschnittlichen Porosität von ungefähr $0,1 \mu \mathrm{m}$.

Summary. A method for preparation of electron microscopic specimens by ultrafiltration can be used for bacteriophages, mycoplasma, and fragile biological particles, especially from solutions containing low concentrations of these particles and when it is necessary to remove also macromolecules up to a certain size.

B. LIŠKA und J. ŠMARDA

Biophysikalisches Institut der Tschechoslowakischen

Akademie der Wissenschaften in Brno und

Biologisches Institut der medizinischen Fakultät der

J.-E.-Purkynè-Universität;

Brno (Tschechoslowakei), 16. Juni 1969

5 M. Rosenberg und J. Šmarda, Česká biol. 4, 449 (1955).

\title{
CONGRESSUS
}

\section{Switzerland The 5th EUCHEM Conference on Stereochemistry}

at the Bürgenstock, near Lucerne, 3-9 May 1970.

The number of participants will be limited. Inquiries and applications should be addressed before 10 January 1970 to the Chairman, Professer E. Havinga, Chemische Laboratoria, Rijksuniversiteit, Postbox 75, Leiden (The Netherlands). 